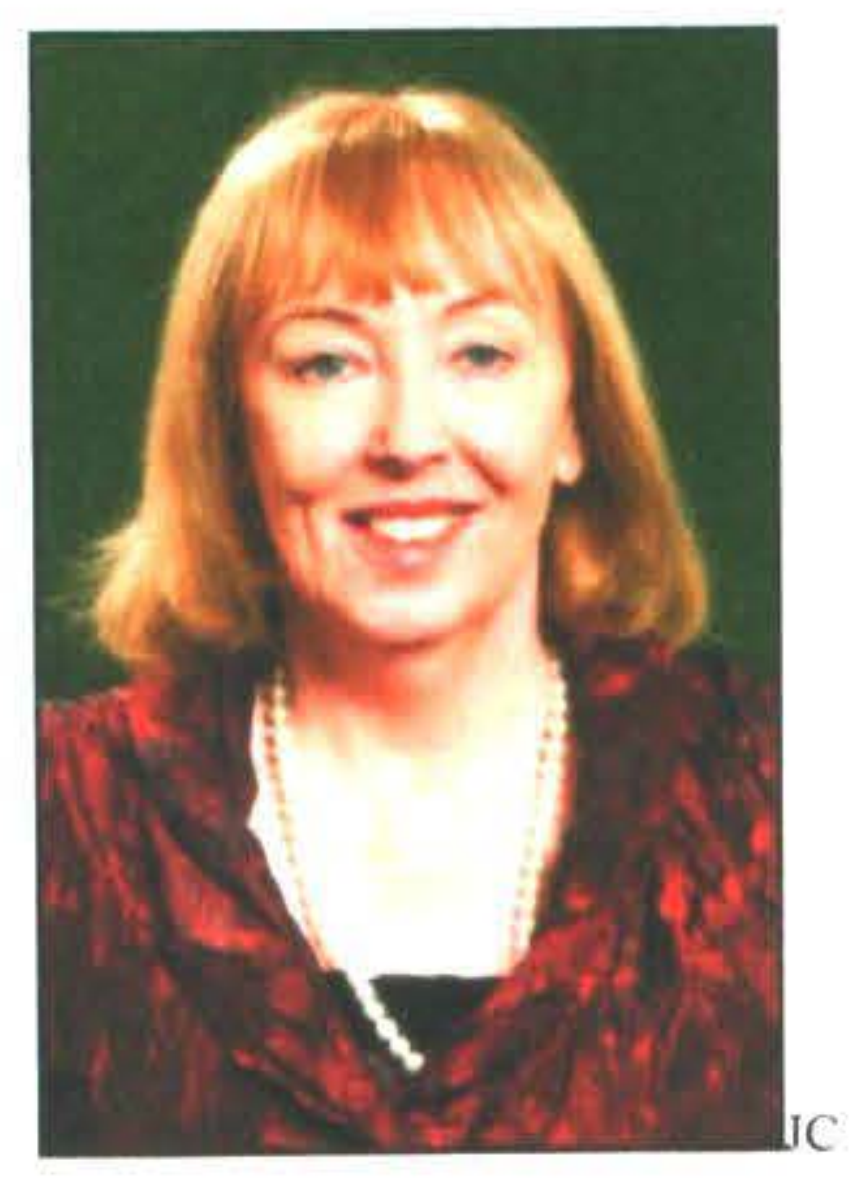

\title{
PLACING MIGRANTS IN \\ EMPLOYMENT: RECRUITMENT CONSULTANTS' EXPERIENCES
}

\author{
Jacqui Campbell and Mingsheng $\mathrm{Li}$
}

\author{
College of Business \\ Massey University, Wellington
}

\begin{abstract}
The purpose of this paper is to discuss the issues that recruitment consultants face when trying to place non-native English speaking professional migrants in employment in New Zealand. Five recruitment consultants participated in two focus groups as part of a wider study conducted in 2007. The consultants in this study worked in the permanent and temporary markets covering a range of professions. Theirs is a highly competitive market, aiming to match candidates with employers to the satisfaction of both. Essentially, the role is a sales one, volume driven and time pressured. Consultants follow the same standard process for all applicants: assessing skills, including communication skills, and preparing three candidates to present to the employer for interview. The perceived differences between migrants and local candidates include difficulties in oral communication; limited knowledge of New Zealand culture, and lack of experience with behavioural interviews. Consultants adopted an educative role towards some highly prejudiced employers. Employers with previous positive experiences with migrants tended to be more receptive. Consultants considered that migrants needed to be more realistic in their job expectations; be prepared to accept contract positions and accept lower level roles initially. They should familiarise themselves with the New Zealand culture, humour and workplace expectations. Current labour market shortages place migrants in a very good position for accessing employment.
\end{abstract}

\section{Introduction}

Recruiting agencies operate on a volume and commercial basis and it is a very competitive industry. In the Wellington region there are 134 employment placement agencies (Statistics New Zealand, 2006). Recruitment consultants work in employment placement agencies, and may be specialists or generalists. Most agencies cater for both temporary and permanent employment. Fixed term contracts are common, and often used by employers in preference to hiring full-time permanent staff. Recruitment consultants view employers as their clients and their first loyalty is to them, working with employers to establish requirements. These are expressed in a job description that details the requirements for a particular position. Employers provide specifications that outline the ideal person for the role. Recruitment consultants act as gatekeepers, identifying a small pool of suitable candidates for the employer to interview. Consultants are paid a base salary and commission, determined by successful placement of candidates who are also viewed as clients. Consultants aim to provide suitable candidates who remain in the positions for a reasonable length of time. Successful placements ensure continued business.

\section{Literature}

Labour skills shortages require organisations to look further afield to meet the talent gap (Ready \& Conger 2007; Abella 2005). Immigration policies are determined by the New Zealand government and change over time.

In recent times changes have been made to immigration policies to maximise the economic benefits of attracting and retaining highly qualified professional migrants by competing with other countries, such as the USA, Canada, Australia, and the UK. In 2006-2007, of the 44,624 people who were granted residency, 13,440 were in the skilled category, making up 48 per cent of total primary residential immigrant application (New Zealand Immigration Service 2007). The top sending countries are China, United Kingdom, India, the Philippines, South Africa, Fiji, USA, Germany, South Korea, and Malaysia (Ready \& Conger 2007).

A survey by the Department of Labour (2006) shows that $81 \%$ employers were satisfied with the performance of the professional migrants they had hired, and $56 \%$ employers reported that their organisations had benefited more from employing migrants than they would have from employing New Zealand residents. The survey also 
found that the hired migrants contributed to the organisations' growth and knowledge and that these professional migrants did not have any problems with the language or with cultural fit within the organisation. Migrants bring positive attitudes, a strong work ethic, and networks with other cultures and immigration is considered as 'an engine of economic growth' (Benson-Rea, Haworth, \& Rawlinson 1998, p. 4). Migrants also bring with them physical, intellectual and financial capital to invigorate the country's economy and to 'ease inflationary pressure' of the country (Nolan 2007).

However, Henderson (2004) believed that the New Zealand policy of immigration selection had achieved little success with regard to the disproportionately high rates of unemployment. Although overseas-born people on the whole are more highly qualified than New Zealand-born people (18 percent have degrees compared with 10 percent locally born, according to the 2001 Census), almost 23 per cent of professional migrants who had lived in New Zealand for less than one year were unemployed (Statistics New Zealand 2004). Professional migrants from North Africa, the Middle East, Northeast Asia, and Southern and Central Asia had the highest unemployment rates (Statistics New Zealand, 2004).

Henderson's (2003) 4-year longitudinal study reveals that most Chinese migrants who found jobs were underemployed, doing jobs unrelated to their qualifications and their professional skills. Although unemployment in New Zealand is low compared with other western countries (Fallow, 2007), Lincoln Tan stressed that finding jobs becomes even more difficult for Asian professional migrants and that the claim that there are good job opportunities for minority ethnic migrants is but a fat lie (Tan 2006a, 2006b). Tan (2006c) warned that denying employment access to migrant professionals would 'destroy New Zealand bit by bit'.

Research conducted by Chang, Morris and Vokes (2006) found that the Korean ethnic group has one of the highest rates of unemployment in New Zealand (at 57\%) and the second lowest level of median income, followed by the Somalian community, most coming to New Zealand on humanitarian grounds. It is apparent that the skills and knowledge of these migrants has remained untapped, unrecognised or under-utilised (Henderson 2003). Many factors may have contributed to such disheartening situations: English language skills, local work experience, qualification recognition, workplace employment discrimination, ethnic and linguistic prejudice and stereotypes, over-qualification for vacancies, lack of government settlement policies, statutory registration, institutional deficiency, and the screening system of recruitment consultants (Trlin, Henderson, \& North 2004; Henderson 2003; Wilson, Gahlout, Liu \& Mouly 2005; Benson-Rea, Haworth \& Rawlinson 1998).
Employment discrimination is often cited as the biggest barrier to accessing employment. According to the Human Rights Commission (2003), the greatest number of complaints $(38 \%)$ was related to racial or ethnic discrimination in employment. In its pilot study of 500 migrants, the New Zealand Immigration Service (2004) found that one in five migrants reported experience of discrimination. Foreign skilled migrants pay an "ethnic penalty' when competing with local residents for jobs (Carmichael \& Woods 2000; Henderson 2004). The penalty varies from one ethnic group to another. Chinese and Indian professional migrants, in particular, are heavily discriminated against - excluded from the labour market by employers and recruitment consultants in their initial job screening on account of their ethnic names and perceived cultural mismatch (Wilson, Gahlout, Liu, \& Mouly 2005). Such a discriminatory effect is psychologically devastating to migrants who wish to do their best to contribute to the New Zealand economy and society (Henderson 2003, 2004; Chang, Morris, \& Vokes 2006).

Research by Butcher, Spoonley and Trlin (2006) and by Chang, Morris and Vokes (2006) also confirmed that a large number of Asian migrants had experienced subtle and implicit discrimination, exclusion and prejudice while seeking employment in New Zealand. Such discrimination based on employers' attitudes towards and perceptions of the applicants' qualifications, language and accents, and work experiences erects barriers that prevent new migrants from gaining employment. Undertaking further training and gaining New Zealand professional or occupational qualifications do not help improve the prospects of employment (Chan 2004). In Butcher, Spoonley and Trlin (2006) one of the participants in that study stated that employment agencies ask migrants to anglicise their names to make them easier to pronounce. The respondent considered that this robs migrants of their identity.

The Hudson survey (2006) of 1705 employers across New Zealand revealed that Kiwi employers still hold 'traditional expectations around employees'. They expected their employees to be 'New Zealandised', and to think and behave in a New Zealand way (Hedquist 2006). With such cocooned mentality, migrant professionals are often blamed for not being equipped with interpersonal communication skills to work alongside Kiwi colleagues. The perceived lack of communication skills rather than technical or professional skills, according to the report, became the biggest obstacle for migrant job seekers. It is ironic that $77 \%$ employers believed that there were barriers to migrants participating successfully in the NZ workforce and yet they were reluctant to employ professionals from overseas even through some key projects fell over because of the severe shortage of professional workers. 


\section{Methodology}

This research was conducted in 2007 in Wellington, New Zealand. Thirty employment agencies who advertise regularly in the regional newspaper were invited to participate. Five recruitment consultants from four agencies participated in two focus groups, each lasting ninety minutes. A qualitative approach was adopted using a semi-structured format. The consultants worked with employers in both the public and private sectors, covering temporary, permanent and short-term contract employment in a diverse range of occupations.

The interview questions were designed to examine the experiences of recruitment consultants in placing professional migrants seeking employment in New Zealand and to find out the issues that could be addressed by migrants to enable them to secure work. The focus groups were audio-taped and transcribed verbatim to facilitate data analysis. A thematic approach was adopted for analysis of the data. For ethical reasons, all the names used in this article are pseudonyms.

\section{Findings}

The consultants in this study identified that inadequate communication skills were perceived to be one of the biggest barriers to employment. They reported that many migrants' language skills were not at a sufficiently high level to be able to communicate in the job. They did not consider that accents in themselves were a barrier but that they could be if they were particularly strong.

Angela explained

I think the hardest thing is that you need good communication and that's a core competency across every single job in this market. It's understanding and the cultural side of it as well in terms of the innuendos and the whole kiwi.

Angela emphasised that language competence is often perceived as being more important than professional skills when recruitment consultants screen their candidates.

Primarily their communication skills, and that's the key, number one thing that I hear all the time. And it's not anything to do with their skills because a lot of the migrants ... most of the migrants that we see are highly skilled, and it's their English skills.

The telephone is a common medium to screen applicants to assess their English language communication skills, especially oral skills. Those without sufficient oral communication skills, or those with strong accents, are often screened out, through telephone conversations or interviews, for positions that require strong communication skills. Language as a barrier prevented many migrants from doing the job similar to or compatible with their prior jobs or qualifications. One recruitment consultant stated that the company had difficulty placing people with backgrounds in finance, management and some other areas that require language skills, but found it easy to place new migrants specialised in IT and accounting where technical or professional skills are more important than face to face communication skills.

The consultants reported that some New Zealand 'conservative' companies or employers would not take risks employing migrants and that clients were concerned about 'otherness' and were unwilling to give migrants the opportunity to prove themselves.

A lack of understanding of kiwi humour was identified as, a barrier to acceptance and integrating with colleagues. Harry identified that humour was important in establishing rapport with clients.

\section{In Bob's view:}

There are situations where the
communication skills aren't at a level to
enjoy a joke, for example... They can't
share a joke, or laugh with the team, because
their backgrounds are such that they cannot
get it.

\section{Immigration Issues}

Initially some migrants have a work permit which allows them to work up to one year. When a permanent job is secured at a level commensurate with their skills and qualifications they can then apply for permanent residency [PR] which entitles the holder to the same rights as New Zealand citizens. The recruitment consultants in this study acknowledged that it was sometimes difficult to keep up to date with changes in immigration policy but that they did attend seminars organised by the New Zealand Immigration Service in an effort to familiarise themselves with the requirements. Mark identified that they have a good website but he considered that it was unlikely that all recruitment consultants or prospective employers would be familiar with the policies.

The recruitment consultants in this study indicated that it is their clients, the employers, who are reluctant to hire people on work visas into permanent positions, saying that 'our clients won't look at them (Angela).' Employers feared that they may experience problems with overstayers. Preference was given to either New Zealand or Australian citizens or New Zealand permanent residents. Harry explained that employers were reluctant to employ people on a work permit because they did not want to become involved in a massive amount of time-consuming paperwork in an attempt to justify employing or retaining a staff member. Employers are required to comply with policies and one 
of the policies is that employers need to prove that they cannot find a suitable New Zealand applicant. Recruitment consultants can sometimes find themselves in the situation of having to provide a guarantee to the employer that if the work permit is not extended then they will find another candidate without charge to the employer.

\section{Discrimination}

Direct discrimination occurs when a person or group is excluded because of personal characteristics; it often arises from prejudices and stereotypes (Stone, 2005). Allport's (1979, p. 4) definition of prejudice says,

\section{Prejudice is an antipathy based on faulty and} inflexible generalisation. It may be felt or expressed. It may be directed toward a group or an individual of that group.

The recruitment consultants in this study said that they would not discriminate themselves but they had experienced discrimination by employers and on occasions had to quote the Human Rights Act 1993. The consultants would not ask migrant applicants to change their names but were aware that this was an issue for some employers.

Previous research has shown that names and ethnicity influence employers' decisions on whether to pursue or reject the application (Wilson, Gahlout, Liu, Mouly \& $\mathrm{Ho}, 2005)$. Angela said that she had one client who was very specific about what he wanted in terms of gender, age and even colour of hair. Frances told of an experience with one client who had rejected a number of candidates:

\section{They eventually listened to us and took somebody on that we presented to them that wasn't anything like they wanted and he's doing an absolutely fantastic job ...}

Harry said that employers had exhibited ageism, racism, sexism and homophobia and that it was a matter of educating them. He identified a number of stereotypes that persist. However, he considered that the tight labour market was forcing employers to consider different types of people. The recruitment consultants in this study acknowledged that when an employer had a particularly good experience with an applicant from a non-dominant cultural group they were more open to diversity in the future.

\section{Intercultural Communication Issues}

Our study suggests that new professional migrants from non-native English-speaking backgrounds are not fully equipped with adequate intercultural communication skills to compete, job-seeking in a new cultural environment. Preparing appropriate professional CVs and letters of application were regarded as an issue that prevented many migrants from being shortlisted for interviews. Bob, one of the recruitment consultants, emphasised that many migrants were unaware of the cultural differences. In some other cultures, the $\mathrm{CV}$ and the covering letter address technical skills whereas in New Zealand they are expected to address the core competencies of the position as described in the job description. According to Frances, her company often ignored serial applicants who did not address the core competence in their applications. The approach of sending serial emails, Frances pointed out, often reduced the chance of obtaining an interview.

Apart from verbal communication issues, non-verbal communication problems were also identified with migrants who obtained interviews. Angela noted that many migrants were familiar with interviews that focused on their technical skills, knowledge and qualifications but were unaccustomed to the behavioural interview that is standard in New Zealand and focuses on applicants' interpersonal skills in an attempt to identify if they are likely to make a good 'team-fit', 'cultural fit' and 'organisational fit', which many employers associate with good retention. Angela stated that Asian migrants, especially females, were often disadvantaged in the interviewing process for their 'submissive' behaviour and indirectness in a culture that emphasises 'assertiveness', 'strong personalities,' openness and straightforwardness:

I guess that's a cultural thing as well, and
especially with females. And it is the
handshake. It is the eye contacts. It is the
initiative, I guess. When you ask them a
question, they just answer. They don't tend
to go into more details.

In Harry's view, their submissive or reserved nature, which is indeed, a cultural thing, prevented them from 'selling' or marketing themselves in spite of their high university qualifications. Bob concluded,

\section{Asian candidates particularly lack, seem to lack that um obvious practical experience and perhaps day-to-day down-to-earth kind of culture we find our clients are looking for.}

Harry said that his company interviewed a candidate for a job in an educational institution. The candidate did not speak a word throughout the entire interview. It was other family members who answered the questions for him 'because it is embarrassing for the candidate to blow their own trumpet.'

Mark identified that many applicants from overseas smoked and the bad smell from smoking was another barrier between immigrants and that prized job. Harry said,

You know when you get into the room it's overpowering or you know they could be as bad as if you've got, you know, shit down your arm. 
Harry said that some candidates were screened out because of their unprofessional telephone behaviour and language problems. He asserted that telephone interviews were an effective ways to judge the applicants' language skills, telephone behaviour or telephone etiquette, and at the same time, to identify the gap between the 'beautifully crafted CV', perhaps written by a professional, and the actual communication competence demonstrated on the phone.

Angela observed that lack of non-verbal communication skills became a real struggle for some migrants, such as ice-breaking, how to initiate and take turns in a conversation, eye contact, grooming, dress, appearances and handshaking. She said that non-verbal communication skills were extremely important in positions where there is high client contact. Candidate who lacked such skills, she claimed would not be employed because they could not make money for the company. As a result, she said, "we teach them [handshaking]. We stand there and we shake their hand until they get it right' [laughs].

\section{Discussion}

This study has revealed many important issues in relation to recruitment consultants placing professional migrants in employment in New Zealand. Some of the findings corroborate with findings by Henderson (2003, 2004) Trlin, Henderson, and North (2004), Benson-Rea, Haworth, and Rawlinson (1998), such as migrants' insufficient English language skills, lack of local work experience and racial discrimination.

Recruitment consultants in this study acknowledge that they act as gatekeepers and they state that employment placement agencies focus on volume, commercial value and throughput. Their goals are to find suitable candidates quickly, match them with clients' expectations, place them and collect their fees. Time spent with applicants does not generate income. Because migrants are new to the country and culture, have little knowledge of the New Zealand workplace culture, greater time is required to prepare them to the standard at which they can be presented to employers. Given that first impressions are very important and that people are often judged within the first few minutes of meeting, pleasantries, icebreakers, handshaking and eye contact can have a significant impact. The cultural norms of New Zealand may be very foreign to migrants in the early days of being in a new country. Furthermore, employers often have high expectations and many are not yet prepared to accommodate diversity. These expectations, according to Angela [consultant], are based on the "similar-to-me" policy, and new migrants are often discriminated against in spite of their skills and professional experience.

Although recruitment consultants have sympathy and empathy for new migrants and they try their best to help them, they cannot change employers' perceptions, prejudice and biases. Harry found that race stereotypes could heavily influence employers' decisions. Such polarised stereotypes make it difficult for people from some ethnic groups to access employment.

Two recruitment consultants in this study suggested that employers need re-educating. They found that New Zealand employers in the private sector were conservative, not easily open to accommodate differences and often unaware of the reservoir of talent migrants bring. By clinging to their comfort zone without endeavouring to reach out and participate in the global competition for talent, these companies miss out on opportunities to win a market niche in globalisation. Positive changes would not take place with the similarto-me effect predominating the psyche of employers. We urge recruitment agencies and employers recognise the potential contribution that migrants bring to the workforce. They should not be excluded on the basis of prejudice, stereotypes and hidden discrimination.

Another important theme that emerges from our study is the importance of intercultural communication skills for professional migrants. Recruitment consultants indicate that lack of intercultural communication skills (verbal and non-verbal communication skills) is a key issue preventing professional migrants from accessing jobs.

\section{Limitations of Study}

This research study is limited in two areas. Despite invitations to many recruitment consultants, only five recruitment consultants participated, limiting the scope of generalisations that can be drawn. On account of funding and time constraints, employers were not invited to participate in the study.

\section{Future Research}

Future research needs to focus on employers' attitudes to migrants. Research on migrants' in employment in specific industries would be helpful to identify where the greatest problems lie. The performance of migrants in particular industries may also be useful.

\section{Conclusion}

This research study found that these particular recruitment consultants recognised the difficulties faced by professional migrants in their attempts to access employment at a level commensurate with their qualifications and previous experience. However, their first obligation was to employers who pay for the service and consultants are keen to establish, build and maintain good relationships with employers to ensure repeat business. As gatekeepers who demonstrate a first loyalty to their clients (employers), they are mainly responsible for these clients who hold high expectations and have 
specific requirements for the candidates. Recruitment consultants require to spend additional time on migrants because preparing candidates from non-English-speaking backgrounds to a standard at which they can be presented to employers requires extra effort. The study recommends that recruitment consultants be more open to migrant applicants, that they encourage employers to diversify their workplaces, be less judgemental towards migrants and to recognise their overseas qualifications and work experience. Recruitment consultants and employers require to maintain currency on immigration policies and recognise that permanent residency is usually a straightforward process after applicants have a firm job offer in an occupation that reflects their qualifications and skill level.

\section{References}

Abella, M. (2005). 'Global competition for skilled workers', Migrations: Observation and Analysis of Contemporary Trends. Retrieved 18 September 2007 from www.ikuspegi.org/documentos/ponencias/ nuevas/M_Abella.pdf

Allport, G. (1979). The nature of prejudice. Boston, Beacon Press.

Benson-Rea, M. Haworth, N. \& Rawlinson, S. (1998). The integration of highly skilled migrants into the labour market: implications for New Zealand business, New Zealand Immigration Service.

Butcher, A., Spoonley, P. \& Trlin, A. (2006). Being accepted: The experience of discrimination and social exclusion by immigrants and refugees in New Zealand, Occasional Publication 13, New Settlers Programme, Massey University, Palmerston North.

Carmichael, F. \& Woods, R. (2000). 'Ethnic penalty in unemployment and occupational attainment: Evidence for Britain', International Review of Applied Economics, vol.14, no. 1, pp.71-81.

Chan, K. (2004). 'Utilising the immigrants we already have', Managing Human Resources Today, vol.65, pp.14-15.

Chang, S., Morris, C. \& Vokes, R. (2006). Korean immigrant families in Christchurch: expectations and experiences, The Families Commission, Wellington.

Department of Labour (2006). Skilled migrants in New Zealand: Employers' perspective, Department of Labour, Wellington.

Fallow, B. (2007). Unemployment hits lowest point since records started. New Zealand Herald,
November 9, 2007. Retrieved November 29, 2007

from:

http://www.nzherald.co.nz/topic/story.cfm?c_id=3 53\&objectid $=10474870$

Firkin, P. Dupuis, A. \& Meares, C. (2004). 'Summary Report: The experiences of professional migrants working in New Zealand'. Retrieved 17 September 2007 from http://1md.massey.ac.nz/publications/ Working $\% 20$ Paper $\% 20$ No13\%20migrants.pdf

Hedquist, U. (2006). 'ICT employers slow to hire migrants', ComputerWorld: The Voice of the ICT Community. Retrieved 18 September 2007 from http://computerworld.co.nz/news.nsf/news/A0467 6110B278FBECC25722200078227

Henderson, A. (2003). Untapped talents: The employment settlement experiences of skilled Chinese in New Zealand. In M Ip (Ed.), Unfolding history, evolving identity: The Chinese in New Zealand (pp. 141-164). Auckland University Press, Auckland.

Henderson, A. (2004). The settlement experiences of immigrants (excluding refugees) in New Zealand: An overview paper completed for the Auckland Regional Settlement Strategy. Palmerston North, New Zealand: International Pacific College.

Hudson 2006. The Hudson Report: Employment and HR Trends (Part Two: HR Insights), Hudson New Zealand, Auckland.

Human Rights Commission (2003). Report of the Human Rights Commission, Human Rights Commission, Wellington.

Masters, C. (2002). 'Rejection a way of life for skilled newcomers', New Zealand Herald. Retrieved November $\quad 12, \quad 2007$ from http://www.nzherald.co.nz/section/1/story. cfm?c_id=1\&objectid $=940700$

Middleton, J. (2005). 'Foreign workers face battle to win jobs', The New Zealand Herald. Retrieved 18 September 2007 from http://www.nzherald.co.nz/ topic/story.cfm?c_id=177\&objectid=10118242

New Zealand Immigration Service (2004). Migrants' experiences of New Zealand: A pilot survey report, New Zealand Immigration Service.

New Zealand Immigration Service (2007). New Zealand Immigration Statistics, New Zealand Immigration Service.

Nolan, M. (2007). 'Don't blame immigrants for inflation'. The Dominion Post, 3 September 2007. 
Ready, D. \& Conger, J. (2007). 'How to fill the talent gap', Business Insight: A Practical Guide to Critical Management Challenges from Today's Leading Experts. Retrieved 18 September 2007 from

http://sloanreview.mit.edu/wsj/insight/leadership/ 2007/09/14/

Statistics New Zealand (2004). Degrees of difference: The employment of university-qualified immigrants in New Zealand.

Statistics New Zealand (2006). L786 100 Employment Placement Services Retrieved 28 November 2007 from http://www.stats.govt.nz/products-andservices/tablebuilder/

Stone, R. J. (2005). Human resource management (5th ed.) John Wiley \& Sons, Queensland, Australia.

Tan, L. (2006a). 'Findings jobs now more difficult for Asian migrants', The New Zealand Herald. Retrieved 18 September 2007 from http://www.nzherald.co.nz/ topic/story.cfm?c_id=147\&objectid=10396003

Tan, L. (2006b). 'Good job opportunities for immigrants just a big fat lie', The New Zealand Herald. Retrieved September 18, 2007 from http://www.nzherald.co.nz/ topic/story.cfm?c_id=147\&objectid=10399496

Tan, L. (2006c). 'Denying immigrants work will destroy NZ bit by bit', The New Zealand Herald. Retrieved September 18, 2007 from http://www.nzherald.co.nz/topic/story.cfm?c_id=1 77 \&objectid $=10401694$

Trlin, A., Henderson, A. and North, N. (2004). Skilled Chinese and Indian immigrant workers. In P. Spoonley, A. Dupuis \& A. DeBruin (Eds.), Work and working in the twenty-first century New Zealand (pp. 205-219). Dunmore Press, Palmerston North, New Zealand.

Wilson, M. G., Gahlout, P., Liu, L. \& Mouly, S. (2005) 'A rose by any other name: The effect of ethnicity and name on access to employment', Business Review, vol.7, no. 2, pp.65-72.

Wilson, M. G., Gahlout, P., Liu, L., Mouly, S. and Ho. M. (2005). 'Three strikes and you're out: The impact of ethnicity, ethnicity of name and immigrant status on access to employment'. Retrieved November 12, 2007 from http://www.newcomersnetwork.com/ $\mathrm{mel} /$ information/research/wilson.doc

\section{Authors}

Jacqui Campbell

Lecturer

Department of Management

Massey University

P.O. Box 756

Wellington 6140

J.A.Campbell@massey.ac.nz

Mingsheng Li

Senior Lecturer

Education

Department of Communication, Journalism and Marketing

Massey University

Private Bag 756

Wellington 6201

M.S.Li@massey.ac.nz 